\title{
Prevalence rate of intimate partner violence by WHO region: an appraisal by current data
}

\author{
Salman Khazaei ${ }^{1}$, Ensiyeh Jenabi ${ }^{2}, *$
}

${ }^{1}$ Department of Epidemiology, School of Public Health, Hamadan University of Medical Sciences, Hamadan, Iran

${ }^{2}$ Pediatric Developmental Disorders Research Center, Hamadan University of Medical Sciences, Hamadan, Iran

\section{Correspondence}

Ensiyeh Jenabi, Pediatric Developmental Disorders Research Center, Hamadan University of Medical Sciences, Hamadan, Iran

Email: en.jenabi@yahoo.com

\section{History}

- Received: 17 October 2018

- Accepted: 01 November 2018

- Published: 18 November 2018

DOI :

https://doi.org/10.15419/ajhs.v4i1.441

\section{Check for updates}

\section{Copyright}

( ) Biomedpress. This is an openaccess article distributed under the terms of the Creative Commons Attribution 4.0 International license.

\section{DEAR EDITOR IN CHIEF}

Intimate partner violence (IPV) is a major public health concern that annually affects 1 in 3 (35\%) of women worldwide. The term "intimate partner violence" defines as physical, sexual, or psychological harm by a current or former partner or spouse ${ }^{1}$.

Women with the characteristics like: low level of education, history of abuse among parents, history of childhood, abuse, antisocial personality disorder, attitudes accepting violence and male privilege are more susceptible to IPV ${ }^{2}$. Consequence of this violence, victims may experience some serious short- and longterm physical, mental, sexual and reproductive health problems such as injuries, chronic pain, gastrointestinal, and gynecological problems including sexuallytransmitted diseases, depression, homicide or suicide, and post-traumatic stress disorders ${ }^{3}$.

According to CDC's National Intimate Partner and Sexual Violence Survey (NISVS), nearly $25 \%$ of adult females and $15 \%$ of adult males have experienced severe physical violence from an intimate partner in their lifetime. This survey showed that the prevalence of sexual contact violence among females and males were $16 \%$ and $7 \%$ respectively ${ }^{4}$. Prevalence rate of IPV by WHO region in 2010 are presented in Figure 1 , as shown the wide variability in levels of violence within and among regions the higher prevalence belong to south East Asia and east Mediterranean regions with $37.7 \%$ and $37 \%$ respectively, the rate of IPV in high income countries was much lower $(23.2 \%)^{5}$. Evidence shows that advocacy and counseling interventions in high-income countries has improved access to services for survivors of IPV and subsequently reducing such violence ${ }^{6}$. It should be noted because of stigmatized and blamed due to received abuse in women; these statistics are prone to underestimation. Based on the above, it is understood that risk of violence is greatest in low resource settings where the use of violence in many situations is a socially-accepted norm. Preventive strategies in these societies should focus on improving the status of women economically and socially as well as reducing norms of violence, poverty, and alcohol consumption ${ }^{7}$.

\section{COMPETING INTERESTS}

The authors declare no conflict of interest in this study.

\section{REFERENCES}

1. for Disease Control C, Prevention. Preventing intimate partner violence 2017; 2017. Available from: https://www.cdc.gov/ violenceprevention/pdf/ipv-factsheet.pdf.

2. World-Health-Organization. Violence against women: Key facts 2017; 2017. Available from: http://www.who.int/news-room/ fact-sheets/detail/violence-against-women.

3. Campbell JC. Health consequences of intimate partner violence. Lancet. 2002;359:1331-6. Available from: Doi:10.1016/ s0140-6736(02)08336-8.

4. Smith SG, Basile KC, Gilbert LK, Merrick MT, Patel N, Walling M, et al. National Intimate Partner and Sexual Violence Survey (NISVS): 2010-2012 state report. 2017;

5. Garcia-Moreno C, Pallitto C, Devries K, Stockl H, Watts C, Abrahams N. Global and regional estimates of violence against women: prevalence and health effects of intimate partner violence and non-partner sexual violence; 2013.

6. Vyas $S$, Watts $C$. How does economic empowerment affect womenś risk of intimate partner violence in low and middle income countries? A systematic review of published evidence. Journal of International Development: The Journal of the Development Studies Association. 2009;21:577-602.

7. Jewkes R. Intimate partner violence: causes and prevention. Lancet. 2002;359:1423-9. Available from: Doi:10.1016/s01406736(02)08357-5. 


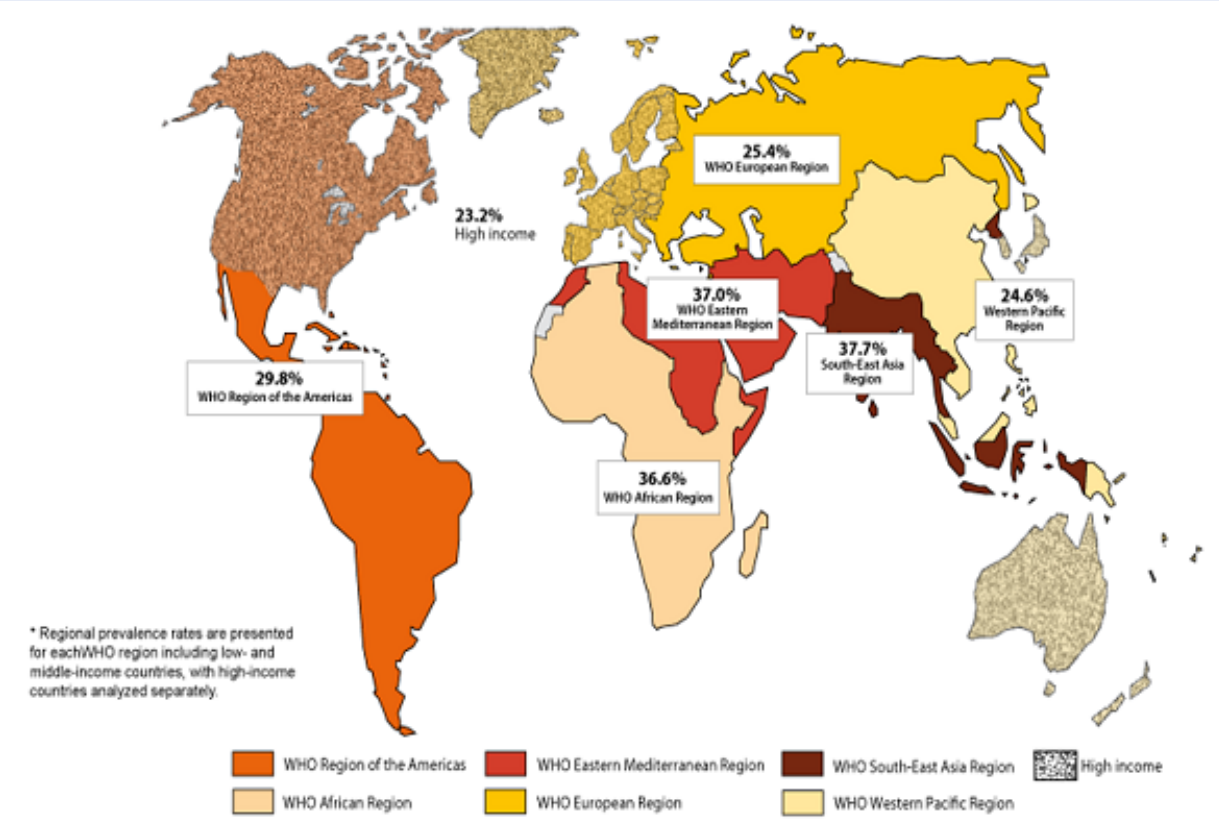

Figure 1: Prevalence rate of intimate partner violence by WHO region in 2010. 